\title{
ANALISIS BIAYA DAN PENDAPATAN USAHA TANI TOMAT DI KABUPATEN GARUT
}

\section{Analysis Of Costs And Revenue Of Tomato Farming Business In Garut Regency}

\author{
Fitri Awaliyah $^{1 *}$, Vela Rostwentivaivi ${ }^{1}$ \\ 1Program Studi Agribisnis Fakultas Pertanian Universitas Garut, \\ Jl. Raya Samarang No. 52A Tarogong Kaler Garut, 44151, Indonesia. \\ *Email : fitriawaliyah@uniga.ac.id
}

\begin{abstract}
ABSTRAK
Kabupaten Garut pada tahun 2018 mempunyai proporsi produksi tomat mencapai 35,46\% dari total produksi tomat keseluruhan di Provinsi Jawa Barat, sehingga mempunyai potensi besar dalam proses budidaya dan akan memberikan manfaat yang besar dalam meningkatkan ekonomi masyarakat Kabupaten Garut. Tujuan penelitian ini adalahuntuk mengaanalisis biaya dan pendapatan usahatani komoditas tomat, agar mengetahui efisiensi dan efektivitas pengelolaan pembudidayaan komoditas tomat di Kabupaten Garut. Penelitian dilakukan di 4 Kecamatan sentra budidaya komoditas tomat yaitu di Kecamatan Cikajang, Cigedug, Cisurupan dan Pasirwangi dengan mewawancarai 40 petani tomat yang diambil secara purposive sampling. Metode analisis yang digunakan adalah metode perhitungan keuntungan dengan cara penerimaan dikurangi biaya total setelah itu menggunakan analisis $\mathrm{R} / \mathrm{C}$ rasio. Hasil penelitian menujukkan bahwa usahatani tomat di Kabupaten Garut mampu memberikan keuntungan terhadap petani dan layak untuk dikembangkan.
\end{abstract}

Kata kata Kunci: Biaya, Pendapatan, Usahatani Tomat, RC Rasio.

\section{ABSTRACT}

Garut Regency in 2018 had a proportion of tomato production reaching $35.46 \%$ of the total tomato production in West Java Province, so it has great potential in the cultivation process and will provide great benefits in improving the economy of the people of Garut 
Regency. The purpose of this study was to analyze the costs and income of tomato farming, in order to determine the efficiency and effectiveness of the management of tomato cultivation in Garut Regency. The study was conducted in 4 sub-districts of tomato cultivation centers, namely Cikajang, Cigedug, Cisurupan and Pasirwangi by interviewing 40 tomato farmers who were taken by purposive sampling. The analytical method used is the method of calculating profits by means of revenues minus total costs after that using the $R / C$ ratio. The results of the study show that tomato farming in Garut Regency is able to provide benefits to farmers and is feasible to be developed.

Keywords: Cost, Income, Tomato Farming, RC Ratio

\section{PENDAHULUAN}

Tomat (Lycopersicum esculentum Miil) merupakan sayuran buah yang tergolong tanaman semusim berbentuk perdu, yang saat ini mempunyai nilai ekonomi tinggi dan masih memerlukan penanganan serius, terutama dalam hal peningkatan hasilnya dan kualitas buahnya (Hanindita, 2008). Komoditas tomat sangat potensial dibudidayakan di Indonesia, karena dapat ditanam secara luas dari mulai dataran redah sampai dataran tinggi. Berdasarkan data Badan Pusat Statistik dan Direktorat Jenderal Hortikultura, sentra produksi komoditas tomat di Indonesia pada tahun 2015 berada di Pulau Jawa dengan mendominasi tingkat produksinya sebesar $47,8 \%$ dari keseluruhan total produksi tomat Indonesia. Wilayah dengan produksi tertinggi terdapat di Provinsi Jawa Barat, di Provinsi Jawa Barat sendiri, produksi tomat terbesar terdapat di Kabupaten Garut.

Tabel 1. Produksi dan Produktivitas Tomat Kabupaten Garut Tahun 2013-2017

\begin{tabular}{ccc}
\hline Tahun & Produksi (Ton) & Produktivitas (Kw/Ha) \\
\hline 2013 & 141.830 & 278,43 \\
2014 & 117.548 & 278,49 \\
2015 & 115.378 & 278,89 \\
2016 & 122.331 & 279,49 \\
2017 & 141.549 & 280,02 \\
\hline Rata-rata & $\mathbf{1 2 7 . 7 2 7 , 2}$ & $\mathbf{2 7 9 , 0 6}$
\end{tabular}

Sumber : Dinas Pertanian Tanaman Pangan dan Hortikultura Kabupaten Garut, 2018. 
Kabupaten Garut mempunyai tingkat produksi tomat pada tahun 2018 mencapai 125.302 ton atau mempunyai proporsi produksi tomat mencapai 35,46\% dar total produksi tomat keseluruhan di Provinsi Jawa Barat. Berikut merupakan data produksi dan produktivitas tanaman tomat di Kabupaten Garut. Kabupaten Garut dikenal dengan pertanian yang subur dan mampu menghasilkan komoditas pertanian unggulan, serta berperan menjadi salah satu kabupaten yang memasok hasil produk hortikultura untuk wilayah lokal, nasional dan ekspor (Maulana, 2018). Dilihat dari Tabel 1 komoditas tomat merupakan salah satu produk hasil pertanian Kabupaten Garut yang menjadi andalan, karena ditinjau dari segi produksinya yang cukup besar. Daerah sentra produksi tomat di Kabupaten Garut adalah Kecamatan Cikajang, Cisurupan, Cigedug dan Pasirwangi.

Tingkat kecocokan agroklimatologi dan topografi tanaman tomat untuk dikembangkan di Kabupaten Garut ini memberikan fakta bahwa Kabupaten Garut mempunyai potensi besar dalam proses budidaya komoditas tomat bila dikelola dengan baik oleh pelaku usahatani. Hal tersebut akan memberikan manfaat yang besar dalam meningkatkan ekonomi masyarakat Kabupaten Garut yang mayoritas adalah sebagai petani. Kajian analisis usahatani komoditas tomat ini akan memberikan gambaran mengenai bagaimana petani mengalokasikan sumberdaya yang dimiliki secara efektif dan efisien untuk mendapatkan keuntungan yang tinggi pada waktu tertentu (Soekartawi, 1995). Sehingga hasil analisis akan diketahui seberapa besar usahatani komoditas tomat mampu menyokong keuntungan finansial bagi petani yang membudidayakannya. Potensi yang besar tersebut tidak serta merta menghilangkan berbagai resiko yang dihadapi dalam pembudidayaan, petani menghadapi berbagai resiko seperti resiko produksi, resiko perubahan harga tomat serta resiko pemasaran lainnya yang berhubungan dengan tingkat ketidakpastian pendapatan usahatani tomat ini. Berdasarkan masalah tersebut maka peneliti melakukan analisis biaya dan pendapatan usahatani komoditas tomat, agar mengetahui efisiensi dan efektivitas pengelolaan pembudidayaan komoditas tomat di Kabupaten Garut. 


\section{METODOLOGI}

\section{Lokasi dan Waktu Penelitian}

Penelitian ini difokuskan pada 4 Kecamatan yaitu Cikajang, Cigedug, Cisurupan, dan Pasirwangi. Pemilihan lokasi dilakukan secara purposive dengan didasarkan pada lokasi sentra luasan panen tomat terbesar di Kabupaten Garut. Penelitian ini dilaksanakan pada bulan April - November tahun 2020.

\section{Jenis dan Sumber Data}

Jenis data yang digunakan dalam penelitian ini adalah data primer yang merupakan hasil observasi dan wawancara di lapangan, seta data sekunder didapatkan dari berbagai referensi, seperti Badan Pusat Statistik (BPS), Pusdatin dan Jurnal.

\section{Teknik Pengumpulan Data dan Pengambilan Sample}

Teknik pengumpulan data dilakukan dengant teknik wawancara terhadap 40 petani tomat yang ditentukan secara purposive (sengaja). Data petani yang digunakan adalah data cross section yang diambil dari data yang bersumber dari petani yang menanam tanaman tomat terakhir pada tahun 2019.

\section{Metode Analisis}

Metode analisis yang digunakan dalam penelitian ini adalah analisis deskriptif kuantitatif. Metode pendekatan deskriptif kuantitatif merupakan metode penelitian yang bertujuan untuk menjelaskan peristiwa atau suatu kejadian yang terjadi dalam bentuk angka-angka yang bermakna. Dalam penelitian ini metode tersebut digunakan untuk mengetahui berapa besar pendapatan petani dalam melakukan usahatani komoditas tomat, dengan cara:

\section{Pendekatan Keuntungan}

Pendekatan ini adalah menghitung keuntungan dengan cara mengidentifikasi total penerimaan dikurangi total biaya. Total penerimaan atau total revenue diperoleh dari harga dikali jumlah produk, sedangkan total biaya 
atau total cost deiperoleh dari hasil perhitungan penjumlahan biaya tetap dan biaya variabel yang digunakan dalam usaha tani. Keuntungan diperoleh berdasarkan hasil perhitungan dari total penerimaan dikurangi total biaya.

$$
\Pi=\mathbf{T R}-\mathbf{T C}
$$

dimana :

$\Pi \quad$ : Keuntungan $(\mathrm{Rp} / \mathrm{Ha})$

TR : Total Revenue (Rp/Ha)

TC : Total Cost (Rp/Ha)

Usahatani dikatakan untung jika mendapatkan hasil keuntungan lebih dari nol $(\Pi>0)$ (Purba, 1997).

\section{Perbandingan antara Penerimaan dan Biaya}

Analisis ini dihitung untuk mengetahui perbandingan penerimaan dengan biaya. Secara matematis dituliskan sebagai berikut :

$$
\begin{gathered}
R / C=T R / T C \\
R / C=\frac{P y \cdot Y}{(F C+V C)}
\end{gathered}
$$

\begin{tabular}{|c|c|}
\hline $\mathrm{R} / \mathrm{C}$ & $=$ Revenue cost ratio \\
\hline Py & $=$ Harga output \\
\hline $\mathrm{FC}$ & $=$ Fixed Cost \\
\hline VC & $=$ Variabel Cost \\
\hline Y & $=$ Jumlah produksi \\
\hline TR & $=$ Total Revenue \\
\hline TC & $=$ Total Cost \\
\hline
\end{tabular}

Dimana :

Dimana apabila nilai $R / C$ usahatani lebih besar dari satu $(R / C>1)$ maka usahatani dianggap menguntungkan dan layak untuk dikembangkan, sebaliknya apabila nilai $\mathrm{R} / \mathrm{C}$ usahatani lebih kecil dari satu $(\mathrm{R} / \mathrm{C}<1)$ maka usahatani dianggap tidak menguntungkan (Purba, 1997). 


\section{HASIL DAN PEMBAHASAN}

\section{Pendekatan Keuntungan}

Pendekatan keuntungan dalam analisis usahatani komoditas tomat ini adalah mengklasifikasikan total penerimaan dan total biaya usahtani yang terdiri dari biaya tetap dan biaya variabel. Penerimaan usahatani tomat dihitung dari hasil produktivitas rata-rata panen tomat per hektar dikali harga rata-rata yang diperoleh sepanjang tahun setiap per kilogram tomat di tingkat petani, perhitungan secara rinci bisa dilihat pada Tabel 2 berikut.

Tabel 2. Rata-rata Penerimaan Usahatani Tomat di Kabupaten Garut

\begin{tabular}{clcc}
\hline No & \multicolumn{1}{c}{ Uraian } & Satuan & Nilai \\
\hline 1. & Produktivitas & $\mathrm{Kg} / \mathrm{Ha}$ & 46.117 \\
2. & Harga & $\mathrm{Rp} / \mathrm{Kg}$ & 3.500 \\
3. & Penerimaan & $\mathrm{Rp}$ & 161.408 .333 \\
\hline
\end{tabular}

Sumber : Data primer, diolah (2020).

Petani tomat melakukan budidaya tomat dalam 1 hektar rata-rata menanam 25.000 tanaman tomat dengan produktivitas rata-rata $1,8 \mathrm{Kg} /$ tanaman, sehingga dalam luasan 1 hektar didapatkan jumlah produksi rata-rata sebesar 46.117 kilogram. Harga tomat pada dasarnya setiap harinya berubah-ubah atau mengalami fluktuasi yang tidak menentu. Harga tomat terendah dalam satu tahun di tingkat petani bisa mencapai $\mathrm{Rp} 500 / \mathrm{Kg}$ dan harga tertinggi bisa mencapai $\mathrm{Rp} 8.000 / \mathrm{Kg}$, harga yang ditetapkan dalam penelitian ini merupakan harga tomat rata-rata yang terjadi sepanjang tahun, yaitu $\mathrm{Rp} 3.500 / \mathrm{Kg}$ di tingkat petani. Hasil perhitungan menunjukkan bahwa petani tomat mendapatkan penerimaan dari hasil penjualan panen tomat sebesar Rp 161.408.333/Hektar per 1 kali musim tanam.

Keuntungan didapatkan dari hasil penerimaan dikurangi biaya total usahatani. Usahatani tomat ini mengeluarkan 2 jenis biaya, yaitu biaya tetap dan biaya variabel. Beberapa biaya yang dikeluarkan tersebut dapat dilihat secara rinci pada Tabel 2. Petani yang membudidayakan komoditas tomat di Kabupaten 
Garut mengeluarkan biaya tetap yang terdiri dari biaya sewa lahan yang ratarata dikeluarkan sebesar Rp2.600.000 per hektar per musim dan biaya penyusutan peralatan rata-rata sebesar Rp623.000, yang biasanya terdiri dari penyusutan alat-alat pertanian berupa cangkul, arit, mesin semprot, pompa dan selang air.

Sedangkan biaya variabel yang digunakan dalam usahatani tomat ini antara lain biaya bibit, pupuk, obat-obatan, tenaga kerja serta penggunaan input lainnya. Petani membudidayakan tomat dengan varietas yang berbeda-beda tergantung ketinggian lahan, namun mayoritas petani menggunakan bibit dengan variaetas yang cocok untuk dataran tinggi. Beberapa merk bibit tomat yang dipakai untuk adalah bibit amala, auratoti, servo dan betavila. Harga bibit pun beragam, namun mayoritas petani lebih banyak menggunakan bibit amala dan auratoti yang cocok ditanam di dataran tinggi, dalam luasan 1 hektar, petani membutuhkan 11 kantong bibit dengan harga rata-rata Rp 185.000/kantong. Pupuk yang digunakan setiap petani mayoritas hampir sama yaitu pupuk kandang, pupuk ZA TSP, NPK dan Ponska. Kebutuhan pupuk untuk setiap luasan 1 hektar antara lain pupuk kandang rata-rata dibutuhkan 1.000 karung dengan harga Rp 18.000/karung, pupuk ZA TSP dibutuhkan 1.500 kilogram dengan harga rata-rata Rp2.500/kg. Pupuk Ponska dibutuhkan 500 kilogram dengan harga rataa-rataa $\mathrm{Rp} 3.000 / \mathrm{kg}$, dan pupuk NPK dibutuhkan 250 kilogram dengan harga rata-rata $\mathrm{Rp} 11.000 / \mathrm{kg}$. Jumlah total biaya pupuk tersebut adalah sebesar Rp26.000.000.

Petani rata-rata menggunakan obat-obatan dalam masa pemeliharaan tanaman tomat. Obat-obatan yang dipergunakan adalah pestisida, fungisida, herbisida, insektisida dan obat penyakit tanaman tomat lainnya, dengan merk yang beragam dan bervariasi. Petani rata-rata menyemprot tanaman tomat dengan obat-obatan sebanyak 2 hari sekali hingga tomat bisa dipanen, sehingga jika diakumulasikan maka petani menyemprot tanaman tomat sebanyak 30 kali dalam setiap kali masa tanam. Biaya obat-obatan untuk luasan 1 hektar rata-rata mencapai Rp 28.260.000.

Tenaga kerja yang digunakan untuk pengolahan lahan biasanya bersifat borongan. Namun untuk pemeliharaan hingga panen biasanya tenaga kerja 
dibayar harian dengan upah berkisar Rp 25.000- 35.000 per hari untuk tenaga kerja perempuan, dan upah tenaga kerja lakilaki berkisar Rp 30.000 - 50.000 . Kegiatan pemeliharaan tanaman tomat meliputi penyemprotan obat-obatan yang dilakukan hingga 20 kali dalam 1 musim, pemberian turus, pemetikan tunas dan pucuk, penyiraman yang hampir dilakukan setiap hari jika musim kemarau, hingga pemetikan buah yang dilakukan 7 sampaik 10 kali hingga tomat habis. Kendala yang sering dirasakan petani yaitu cuaca, jika musim hujan petani akan banyak memberikan obat-obatan sebanyak 20-25 kali sehingga biaya obat-obatan akan naik, sedangkan di saat musim kemarau petani akan banyak mengeluarkan biaya untuk tenaga kerja penyiraman. Jumlah biaya tenaga kerja untuk luasan penanaman 1 Hektar dari mulai pengolahan lahan hingga panen adalah sebesar $\operatorname{Rp} 26.310 .000$.

Sedangkan biaya penggunaan input lainnya petani mengeluarkan biaya sebesar Rp 18.587 .500 yang dikeluarkan untuk membeli turus atau kayu penopang tanaman tomat, tali rafia, tali majur, mulsa, biaya angkut turus serta biaya angkut pupuk. Keseluruhan biaya total usahatani tomat adalah sebesar Rp 104.415.663 per hektar untuk 1 kali musim tanam. Jika produktivitas tomat per hektar adalah 46.117 kilogram maka biaya total untuk setiap kilogram tomat adalah Rp2.264. Keuntungan usahatani tomat ini diperoleh dari penerimaan dikurangi biaya, dimana penerimaannya adalah sebesar Rp161.408.333 dan biaya usahatani sebesar Rp104.415.663 sehingga keuntungan yang didapatkan sebesar Rp56.992.670 per hektar untuk 1 kali musim tanam, hal tersebut menunjukkan bahwa keuntungan di atas angka 0, yang berarti usahatani tomat memberikan keuntungan bagi petani. 
Tabel 2. Komponen Biaya Usahatani Tomat per Hektar Per Musim Tanam

\begin{tabular}{|c|c|c|c|c|c|}
\hline NO & Komponen Biaya & Banyaknya & Satuan & Harga & Jumlah \\
\hline \multicolumn{6}{|c|}{ Biaya Tetap } \\
\hline 1 & Sewa lahan & 1 & \multirow[t]{2}{*}{ Ha } & \multirow[t]{2}{*}{1.600 .000} & 2.600 .000 \\
\hline 2 & $\begin{array}{l}\text { Biaya penyusutan } \\
\text { peralatan }\end{array}$ & 1 & & & 623.163 \\
\hline & Jumlah & & & & 3.223 .163 \\
\hline \multicolumn{6}{|c|}{ Biaya Variabel } \\
\hline \multicolumn{6}{|c|}{ Bibit } \\
\hline \multirow[t]{2}{*}{3} & Bibit & 11 & Kantong & 185.000 & 2.035 .000 \\
\hline & Jumlah & & & & 2.035 .000 \\
\hline \multicolumn{6}{|c|}{ Pupuk } \\
\hline 4 & Pupuk Kandang & 1.000 & Karung & 18.000 & 18.000 .000 \\
\hline 5 & Pupuk ZA TSP & 1.500 & $\mathrm{Kg}$ & 2.500 & 3.750 .000 \\
\hline 6 & Pupuk Ponska & 500 & $\mathrm{Kg}$ & 3.000 & 1.500 .000 \\
\hline \multirow[t]{2}{*}{7} & Pupuk NPK & 250 & $\mathrm{Kg}$ & 11.000 & 2.750 .000 \\
\hline & Jumlah & & & & 26.000 .000 \\
\hline \multicolumn{6}{|c|}{ Obat-obatan } \\
\hline 8 & Daconil & 96 & Kantong & 100.000 & 9.600 .000 \\
\hline 9 & Victori & 96 & Botol & 60.000 & 5.760 .000 \\
\hline 10 & Amistar & 10 & Botol & 240.000 & 2.400 .000 \\
\hline 11 & Supergrow & 24 & Botol & 35.000 & 840.000 \\
\hline 12 & Prepaton & 10 & Kantong & 150.000 & 1.500 .000 \\
\hline 13 & Calsium & 96 & Botol & 25.000 & 2.400 .000 \\
\hline \multirow[t]{2}{*}{14} & Sirodan & 96 & Botol & 60.000 & 5.760 .000 \\
\hline & Jumlah & & & & 28.260 .000 \\
\hline \multicolumn{6}{|c|}{ Tenaga Kerja } \\
\hline 15 & Pengolahan lahan & 1 & $\mathrm{Ha}$ & 15.000 .000 & 15.000 .000 \\
\hline 16 & Penanaman & 43 & $\mathrm{HOK}$ & 30.000 & 1.290 .000 \\
\hline 17 & Pemasangan Turus & 43 & $\mathrm{HOK}$ & 30.000 & 1.290 .000 \\
\hline 18 & Pemasangan Tali & 63 & $\mathrm{HOK}$ & 30.000 & 1.890 .000 \\
\hline 19 & Pemotongan Pucuk & 63 & $\mathrm{HOK}$ & 30.000 & 1.890 .000 \\
\hline 20 & Pemetikan tunas & 29 & $\mathrm{HOK}$ & 30.000 & 870.000 \\
\hline 21 & $\begin{array}{l}\text { Penyemprotan Obat- } \\
\text { obatan }\end{array}$ & 80 & $\mathrm{HOK}$ & 30.000 & 2.400 .000 \\
\hline \multirow[t]{2}{*}{22} & Panen & 56 & $\mathrm{HOK}$ & 30.000 & 1.680 .000 \\
\hline & Jumlah & & & & 26.310 .000 \\
\hline \multicolumn{6}{|c|}{ Penggunaan Input Lainnya } \\
\hline 23 & Turus & 27.000 & pcs & 300 & 8.100 .000 \\
\hline 24 & Tali Rapia & 20 & Pcs & 15.000 & 300.000 \\
\hline 25 & Mulsa & 10 & Pcs & 650.000 & 6.500 .000 \\
\hline 26 & Biaya angkut turus & 250 & ikat & 2.500 & 625.000 \\
\hline 27 & Biaya angkut pupuk & 1.045 & Karung & 2.500 & 2.612 .500 \\
\hline \multirow[t]{4}{*}{28} & Tali majur & 30 & PCS & 15.000 & 450.000 \\
\hline & Jumlah & & & & $\mathbf{1 8 . 5 8 7 . 5 0 0}$ \\
\hline & Total Biaya & & & & 104.415 .663 \\
\hline & Biaya Per kilogram & & & & 2.264 \\
\hline
\end{tabular}

Sumber : Data primer, diolah (2020). 


\section{Perbandingan antara Penerimaan dan Biaya}

Melihat Tabel 2 dan 3 mengenai penerimaan dan biaya usahatani tomat di Kabupaten Garut, dapat di hitung R/C rasionya yaitu :

\section{Revenue Cost Ratio $=\mathrm{Rp} 161.408 .333 / \mathrm{Rp} 104.415 .663=1,546$}

Hasil perhitungan menunjukkan angka 1,54 yang menunjukkan bahwa R/C > 1 yang artinya adalah penerimaan lebih besar dari biaya yang dikeluarkan, atau dengan kata lain setiap Rp 1 biaya yang dikeluarkan mampu menghasilkan penerimaan sebesar Rp1,54, sehingga dapat disimpulkan bahwa usahatani tomat di Kabupaten Garut layak untuk dikembangkan dan menghasilkan keuntungan bagi para petani. Hasil perhitungan R/C rasio tersebut sama dengan hasil penelitian yang pernah dilakukan oleh Fadli tahun 2014 yang menunjukkan bahwa usahatani tomat di Kecamatan Tatanga Kota Palu menghasilkan perhitungan $\mathrm{R} / \mathrm{C}$ rasio sebesar 1,76 .

\section{KESIMPULAN DAN REKOMENDASI KEBIJAKAN}

Hasil penelitian mengungkapkan bahwa biaya usahatani tomat di Kabupaten Garut per hektar setiap kali musim tanam adalah sebesar Rp104.415.663, dengan penerimaan sebesar Rp161.408.333, sehingga petani mendapatkan keuntungan sebesar Rp56.992.670. Hasil perhitungan R/C rasio menunjukkan angka 1,54 yang artinya $\mathrm{R} / \mathrm{C}>1$ dimana penerimaan lebih besar dari biaya yang dikeluarkan, atau dengan kata lain setiap $\operatorname{Rp} 1$ biaya yang dikeluarkan mampu menghasilkan penerimaan sebesar Rp1,54, sehingga usahatani tomat di Kabupaten Garut layak untuk dikembangkan dan menghasilkan keuntungan bagi para petani. Rekomendasi kebijakan yang dapat diberikan dari hasil penelitian, melihat harga tomat yang sangat fluktuatif, diharapkan pemerintah dan stakeholder mendorong kesempatan untuk mengolah hasil panen tomat untuk mengantisipasi ketika harga tomat berada pada kondisi yang sangat rendah, sehingga bisa dimanfaatkan untuk industri pengolahan. 


\section{UCAPAN TERIMAKASIH}

Penulis mengucapkan terimakasih kepada Kemenristekdikti atas pelaksanaan Penelitian Dosen Pemula tahun 2020.

\section{DAFTAR PUSTAKA}

Fadli, Saddam. 2014. Analisis Pendapatan dan Kelayakan Usahatani Tomat di Keluaraha Boyaoge Kecamatan Tatanga Kota Palu. Jurnal Agroland.Vol 21 No 1. $45-48$.

Hanindita, Nisa. 2008. Analisis Ekspor Tomat Segar Indonesia. Bogor: Program Pascasarjana Manajemen Bisnis Institut Pertanian Bogor.

Maulana, Septian. 2018. Zonasi Kesesuaian Agroklimat untuk Menentukan

Wilayah Potensial Pengembangan Tanaman Tomat (Lycopersicum Esculetum Miil) di Kabupaten Garut. Skripsi. Universitas Pendidikan Indonesia.

Purba, R. 1997. Analisis Biaya dan Manfaat. Cetakan Pertama, Rineke Cipta, Yogyakarta.

Soekartawi. (1995). Analisis Usahatani. Universitas Indonesia. 